\title{
6q25.1-q25.3 Microdeletion in a Chinese Girl
}

\author{
(1) Mian-Ling Zhong ${ }^{1}$, (1) Ye-Mei Song ${ }^{1,2}$, (1) Chao-Chun Zou ${ }^{1}$ \\ ${ }^{1}$ Children's Hospital of Zhejiang University Faculty of Medicine, Department of Endocrinology; National Clinical Research Center for Child Health, \\ Huzhou, China \\ ${ }^{2}$ Huzhou Center Hospital, Clinic of Pediatrics, Huzhou, China
}

\section{What is already known on this topic?}

6 q25 microdeletion, a rare chromosome disorder, has been associated with growth restrictions, abnormal head shape, craniofacial anomalies, hypotonia, seizures, and mild to moderate intellectual disability.

\section{What this study adds?}

We reported a Chinese patient with an 8.1-Mb deletion involving 6q25.1-q25.3. Our patient shared the phenotypic features of the 6q25 microdeletion, including dysmorphic features with dysgenesis of the corpus callosum, growth retardation, intellectual disability, and language delay. In patients with dysmorphic features, microcephaly, growth retardation, intellectual disability, language delay and corpus callosum dysgenesis, 6q25 microdeletion should be considered in the differential diagnosis and chromosomal microarray analysis should be performed to confirm the diagnosis.

\section{Abstract}

Deletions of the long arm of chromosome 6 are rare and are characterized by great clinical variability according to the deletion breakpoint. Herein, we reported a 3-year-old girl evaluated for facial dysmorphism (long and connected eyebrows, big mouth, wide nasal bridge, high palatine arch, low set ears, and thin hair), growth retardation, intellectual disability, and language delay. Chromosomal microarray analysis revealed an 8.1-Mb deletion within 6q25.1-q25.3 ([hg19] chr6: 152,307,705-160,422,834) comprising 31 genes. Dysmorphic features, microcephaly, intellectual disability, language delay, growth retardation, and corpus callosum dysgenesis were commonly reported. Hence, 6q25 microdeletion is a rare condition. In patients with dysmorphic features, microcephaly, growth retardation, intellectual disability, language delay and corpus callosum dysgenesis, 6q25 microdeletion should be considered in the differential diagnosis and chromosomal microarray analysis should be performed to confirm the diagnosis.

Keywords: 6q25 microdeletion, facial dysmorphism, growth retardation, intellectual disability, language delay

\section{Introduction}

6q25 microdeletion, a rare chromosome disorder, has been associated with growth restrictions, abnormal head shape, craniofacial anomalies, hypotonia, seizures, and mild to moderate intellectual disability $(1,2)$. Although a genotypephenotype correlation has initially been proposed based on the proximal, medial, and distal location of the deletions, the reported cases with molecular karyotyping showed significant clinical heterogeneity, even with overlapping deletions $(3,4)$. Most cases also share delayed verbal communication abilities, although detailed descriptions of speech have not generally been reported (5). $6 q 25$ microdeletion has been extremely rare since the first report in 1975 (6). Herein, we reported a 3-year-old girl with 6q25 microdeletion to highlight this rare condition.

\section{Case Report}

The female patient was the first child of healthy nonconsanguineous parents. Family history was negative for neurological disorders, behavioral problems, or congenital anomalies. She was born at $39^{+4}$ weeks gestation via
Address for Correspondence: Chao-Chun Zou MD, Children's Hospital of Zhejiang University Faculty of Medicine, Department of Endocrinology, Huzhou, China Phone: +86-571-87033296 E-mail: zcc14@zju.edu.cn ORCID: orcid.org/0000-0002-4667-3636

${ }^{\circ}$ Copyright 2021 by Turkish Pediatric Endocrinology and Diabetes Society

The Journal of Clinical Research in Pediatric Endocrinology published by Galenos Publishing House.
Conflict of interest: None declared Received: 16.01 .2020 Accepted: 25.03 .2020 
vaginal delivery with uneventful pregnancy. Her birth weight and length were $2,600 \mathrm{~g}$ and $48 \mathrm{~cm}$ without documented occipital frontal circumference and APGAR. After birth, feeding difficulty was noted without history of nasal feeding. Her global development was delayed, with no improvement in her developmental skills with age. She could sit at the age of 15 months, and crawl at the age of two years old. She could not walk without support at the age of 37 months. She could only call "Dad" and "Grandma" at the age of 39 months.

She was first presented to our outpatient clinic at the age of 37 months because of growth retardation, intellectual disability, and language delay. Physical examination showed a height of $85.8 \mathrm{~cm}$ [ $<-2$ standard deviation (SD)] and a weight of $11.8 \mathrm{~kg}(-1 \sim-2 \mathrm{SD})$. Characteristic facial dysmorphism, including long and connected eyebrows, big mouth, wide nasal bridge, high palatine arch, low set ears, and thin hair was noted. The heart, lung, abdomen, limb, and muscle tension were unremarked. Brain magnetic resonance imaging (MRI) revealed dysmorphism of the corpus callosum and stronger T2 signal at basal ganglia.

Standard chromosome banding analysis performed in a local hospital reported "balanced translocation" in chromosome 4 and 8 for this patient and no abnormality for her parents. Chromosomal microarray analysis (CMA) (CMA, CytoScan ${ }^{\circledR}$ HD, Affymetrix) performed in our Medical Genetics Laboratory did not find any microdeletion or microduplication in chromosome 4 or 8 , but identified an 8.1-Mb deletion in 6q25.1-q25.3 ([hg19]chr6:152,307,705160,422,834), which covered 31 genes (ESR1, SYNE1, MYCT1, VIP, FBXO5, MTRF1L, RGS17, OPRM1, CNKSR3, SCAF8, TIAM2, TFB1M, NOX3, ARID1B, SNX9, SYNJ2, SERAC1, GTF2H5, TMEM181, DYNLT1, EZR, RSPH3, TAGAP, FNDC1, SOD2, WTAP, ACAT2, TCP1, MRPL18, MAS1 and $I G F 2 R)$, as shown in Figure 1.

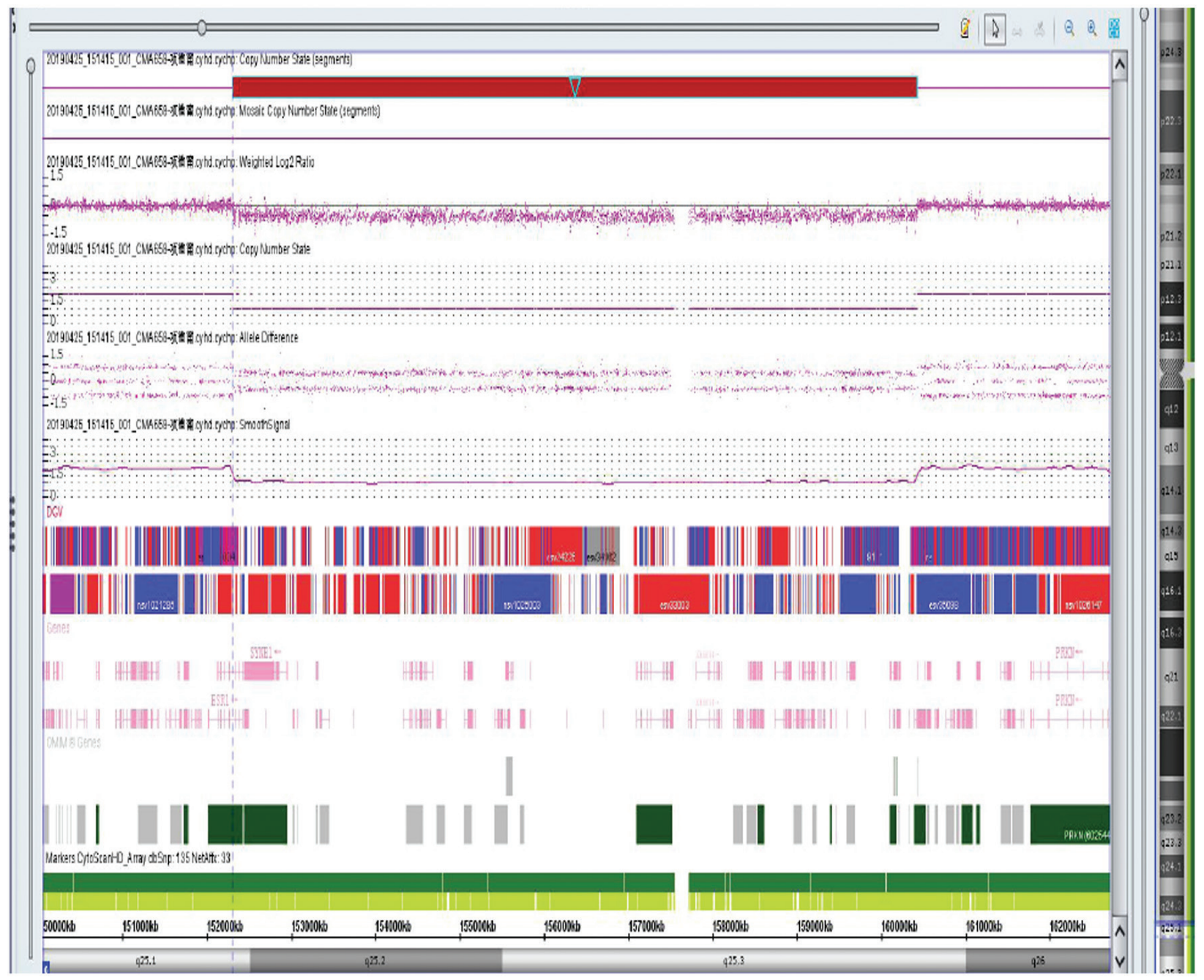

Figure 1. Chromosomal microarray analysis showed an 8.1-Mb deletion in 6q25.1-q25.3 (152,307,705-160,422,834), which covered 31 genes $(100 \times 65.9 \mathrm{~mm})$ 


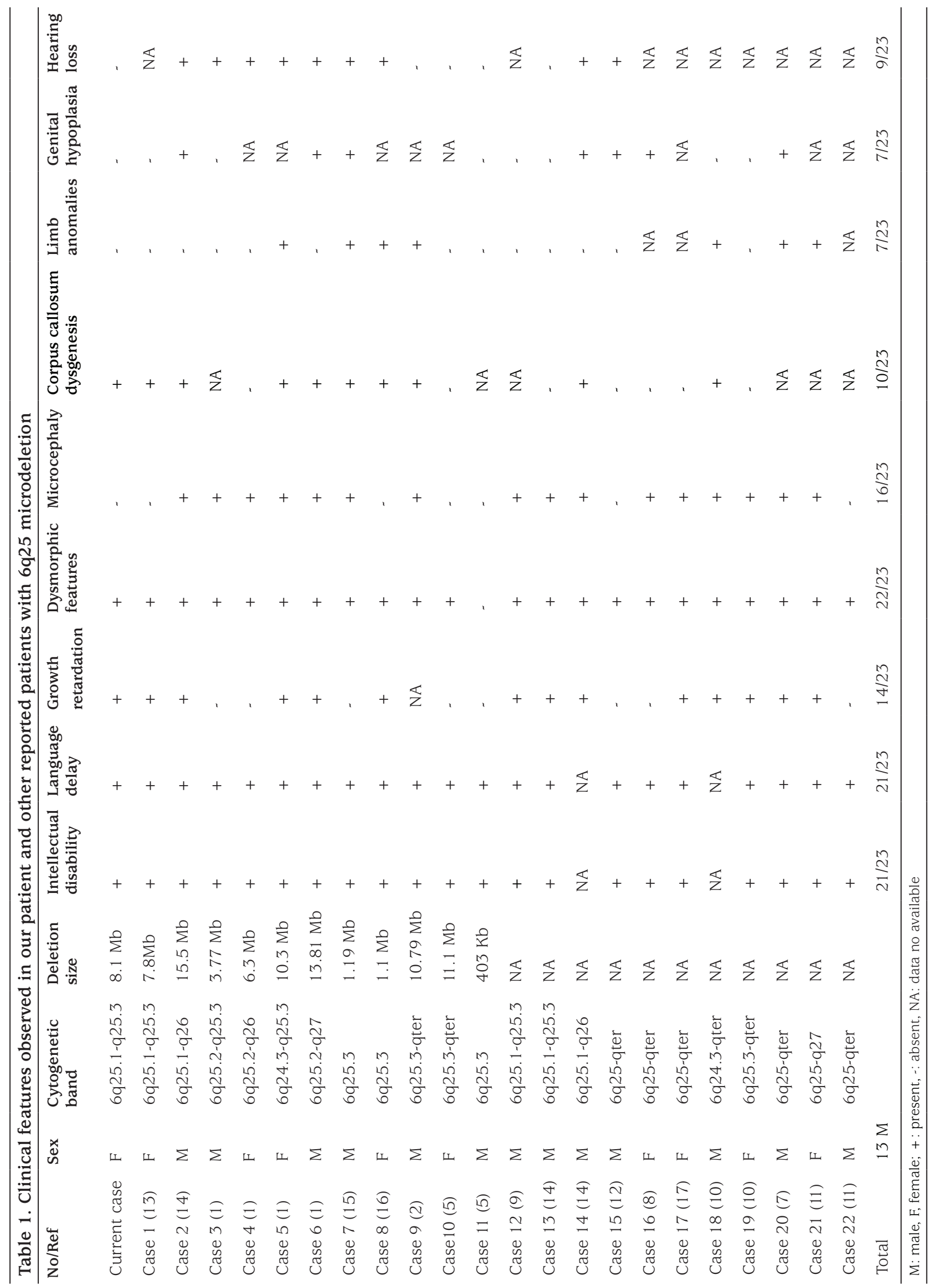




\section{Discussion}

Interstitial deletions of the long arm of chromosome 6 are rare. Since the first report in 1975 (6), the number of patients that have been described in the medical literature remains few $(1,2,5,7,8,9,10,11,12,13,14,15,16,17)$. The phenotype of this syndrome is variable and depends on the breakpoints, location and size of the deletion. Facial dysmorphism, hand malformations, heart defects, microcephaly, intellectual disability, epilepsy, and other neurodevelopmental and neuropsychiatric conditions have been reported. A comparison of the clinical characteristics of our patients with those reported in the literature is shown in Table 1. The clinical features observed in our patient and the other 22 previously reported patients showed that 22 (95.7\%) had dysmorphic features, 21 (91.3\%) had intellectual disability and language delay, 16 (69.6\%) had microcephaly, 14 (60.9\%) had growth retardation, and $10(43.5 \%)$ had corpus callosum dysgenesis. The clinical characteristics of our patient overlap with several of these patients. The most common ones include growth retardation, intellectual disability, language delay, and dysmorphic features as well as dysgenesis of the corpus callosum, while microcephaly, hearing loss, limb anomalies and genital hypoplasia are not noted in our patient. These differences may be partly attributed to the varying size and breakpoints of the deletion and more importantly, the gene content of the deleted segment (18). In our patient, CMA showed an 8.1-Mb deletion of 6q25.1-q25.3, which covers 31 genes and only four of these genes (ARID1B, IGF2R, TIAM2 and SYNJ2) have been associated with pathogenicity. Short stature was observed in our patient, while it was not noted in some previous cases $(5,8,11,12,15)$. This may be due to the deletion of the IGF2R gene in our patient. Most other case reports do not specify the deleted genes so further comparison is not possible. However, studies of mice have supported a major role for the $I G F$ receptor pathway in growth: knockout of IGF1, IGF2, or IGF1R results in growth retardation, whereas overexpression of IGF2 results in overgrowth $(19,20)$. The identification of an IGF2 mutation in patients with growth restriction suggests that IGF2 is not only a mediator of intrauterine development but also contributes to postnatal growth (21). The importance of other deleted genes and their contribution to the 6q25 microdeletion are uncertain at this time. Additionally, links between brain anomalies and language delay has been noted in the literature. For instance, de Vasconcelos Hage et al (22) reported that 13 cases of perisylvian polymicrogyria and three cases of corpus callosum hypoplasia were found in 17 patients with language impairment. In typically developing young children, the developmental rate of the splenium of the corpus callosum was associated with vocabulary size (23). In individuals with disfluent speech, the anterior corpus callosum showed significantly lower fractional anisotropy than that of typical controls (24). Hence, in patients with dysmorphic features, microcephaly, intellectual disability, language delay, and corpus callosum dysgenesis, 6q25 microdeletion should be considered in the differential diagnosis and CMA should be performed to confirm the diagnosis.

The mechanism of 6 q25 microdeletion is still unclear. The smallest critical region described so far for $6 q 25$ microdeletion have restricted to a 6 q25.3 region including two protein-coding genes, ARID1B and ZDHHC14 which was considered to be responsible for the cognitive impairment and brain anomalies observed in their patients (15). The core phenotypic characteristics associated with the 6q25 microdeletion have been observed in a child with a deletion involving only $A R I D 1 B$ which suggested that ARID1B may be one key gene associated with these features (16). Additionally, $A R I D 1 B$ has been associated with multiple syndromes characterized by developmental delay and intellectual disability, such as Coffin-Siris syndrome, and with non-syndromic intellectual disability. It is reported that $A R I D 1 B$ is of great importance for normal human brain development and function. In one study, the phenotypegenotype correlation in seven patients who had varioussized deletions including $A R I D 1 B$, has shown that haploinsufficiency of $A R I D 1 B$ is related with intellectual disability, speech impairment, and autism as well as corpus callosum abnormalities (25). Therefore, haploinsufficiency of $A R I D 1 B$ appears to be responsible for the clinical findings in our patient.

\section{Conclusion}

In summary, 6q25 microdeletion is a rare condition. In patients with dysmorphic features, microcephaly, growth retardation, intellectual disability, language delay, and corpus callosum dysgenesis, 6q25 microdeletion should be considered in the differential diagnosis and CMA should be performed to confirm the diagnosis. MRI of the brain should be considered in all patients with deletions involving 6q25.

\section{Acknowledgment}

The authors would like to express their gratitude to the participating family.

\section{Ethics}

Informed Consent: Written informed consent was obtained from the parents. 


\section{Peer-review: Externally peer-reviewed.}

\section{Authorship Contributions}

Concept: Mian-Ling Zhong, Chao-Chun Zou, Design: MianLing Zhong, Ye-Mei Song, Chao-Chun Zou, Data Collection or Processing: Mian-Ling Zhong, Ye-Mei Song, Literature Search: Mian-Ling Zhong, Ye-Mei Song, Chao-Chun Zou, Writing: Mian-Ling Zhong.

Financial Disclosure: The authors have indicated that they have no financial relationships relevant to this article to disclose.

\section{References}

1. Nagamani SC, Erez A, Eng C, Ou Z, Chinault C, Workman L, Coldwell J, Stankiewicz P, Patel A, Lupski JR, Cheung SW. Interstitial deletion of 6q25.2-q25.3: a novel microdeletion syndrome associated with microcephaly, developmental delay, dysmorphic features and hearing loss. Eur J Hum Genet 2009;17:573-581. Epub 2008 Nov 26

2. Abu-Amero KK, Hellani A, Salih MA, Al Hussain A, al Obailan M, Zidan G, Alorainy IA, Bosley TM. Ophthalmologic abnormalities in a de novo terminal 6q deletion. Ophthalmic Genet 2010;31:1-11.

3. Klein OD, Cotter PD, Moore MW, Zanko A, Gilats M, Epstein CJ, Conte $\mathrm{F}$, Rauen KA. Interstitial deletions of chromosome 6q: genotypephenotype correlation utilizing array CGH. Clin Genet 2007;71:260266.

4. G Girirajan S, Rosenfeld JA, Coe BP, Parikh S, Friedman N, Goldstein A, Filipink RA, McConnell JS, Angle B, Meschino WS, Nezarati MM, Asamoah A, Jackson KE, Gowans GC, Martin JA, Carmany EP, Stockton DW, Schnur RE, Penney LS, Martin DM, Raskin S, Leppig K, Thiese H, Smith R, Aberg E, Niyazov DM, Escobar LF, El-Khechen D, Johnson KD, Lebel RR, Siefkas K, Ball S, Shur N, McGuire M, Brasington CK, Spence JE, Martin LS, Clericuzio C, Ballif BC, Shaffer LG, Eichler EE. Phenotypic heterogeneity of genomic disorders and rare copy-number variants. $\mathrm{N}$ Engl J Med 2012;367:1321-1331. Epub 2012 Sep 12

5. Peter B, Lancaster H, Vose C, Fares A, Schrauwen I, Huentelman M. Two unrelated children with overlapping 6 q25.3 deletions, motor speech disorders, and language delays. Am J Med Genet A 2017;173:26592669. Epub 2017 Aug 2

6. Milosevic J, Kalicanin P. Long arm deletion of chromosome no. 6 in a mentally retarded boy with multiple physical malformations. J Ment Defic Res 1975;19:139-144.

7. Bartoshesky L, Lewis MB, Pashayan HM. Developmental abnormalities associated with long arm deletion of chromosome No. 6. Clin Genet 1978;13:68-71.

8. Oliveira-Duarte MH, Martelli-Soares LR, Sarquis-Cintra T, Machado ML, Lison MP. Distal monosomy of the long arm of chromosome 6 (6q25-6qter) inherited by maternal translocation t (6q;17q). Ann Genet 1990;33:56-59.

9. Narahara K, Tsuji K, Yokoyama Y, Namba H, Murakami M, Matsubara T, Kasai R, Fukushima Y, Seki T, Wakui K, et al. Specification of small distal $6 q$ deletions in two patients by gene dosage and in situ hybridization study of plasminogen and alpha-L-fucosidase 2. Am J Med Genet 1991;40:348-353.

10. Meng J, Fujita H, Nagahara N, Kashiwai A, Yoshioka Y, Funato M. Two patients with chromosome $6 \mathrm{q}$ terminal deletions with breakpoints at q24.3 and q25.3. Am J Med Genet 1992;43:747-750.
11. Valtat C, Galliano D, Mettey R, Toutain A, Moraine C. Monosomy 6q: report on four new cases. Clin Genet 1992;41:159-166.

12. Hopkin RJ, Schorry E, Bofinger M, Milatovich A, Stern HJ, Jayne C, Saal HM. New insights into the phenotypes of $6 \mathrm{q}$ deletions. Am J Med Genet 1997;70:377-386

13. Pirola B, Bortotto L, Giglio S, Piovan E, Janes A, Guerrini R, Zuffardi O. Agenesis of the corpus callosum with Probst bundles owing to haploinsufficiency for a gene in an $8 \mathrm{cM}$ region of 6q25. J Med Genet 1998;35:1031-1033

14. Sukumar S, Wang S, Hoang K, Vanchiere CM, England K, Fick R, Pagon $\mathrm{B}$, Reddy KS. Subtle overlapping deletions in the terminal region of chromosome 6q24.2-q26: three cases studied usi ng FISH. Am J Med Genet 1999;87:17-22

15. Michelson M, Ben-Sasson A, Vinkler C, Leshinsky-Silver E, Netzer I, Frumkin A, Kivity S, Lerman-Sagie T, Lev D. Delineation of the interstitial 6q25 microdeletion syndrome: refinement of the critical causative reg ion. Am J Med Genet A 2012;158:1395-1399. Epub 2012 May 14

16. Ronzoni L, Tagliaferri F, Tucci A, Baccarin M, Esposito S, Milani D. Interstitial 6q25 microdeletion syndrome: ARID1B is the key gene. Am J Med Genet A 2016;170:1257-1261. Epub 2016 Jan 11

17. Rivas F, Ruiz C, Rivera H, Möller M, Serrano-Lucas JI, Cantú JM. De novo del(6)(q25) associated with macular degeneration. Ann Genet 1986;29:42-44.

18. Paulraj P, Palumbos JC, Openshaw A, Carey JC, Toydemir RM. Multiple Congenital Anomalies and Global Developmental Delay in a Patient with Interstitial 6q25.2q26 Deletion: A Diagnostic Odyssey. Cytogenet Genome Res 2018;156:191-196. Epub 2018 Nov 16

19. Baker J, Liu JP, Robertson EJ, Efstratiadis A. Role of insulin-like growth factors in embryonic and postnatal growth. Cell 1993;75:73-82.

20. Fowden AL. The insulin-like growth factors and feto-placental growth. Placenta 2003;24:803-812

21. Begemann M, Zirn B, Santen G, Wirthgen E, Soellner L, Büttel HM, Schweizer R, van Workum W, Binder G, Eggermann T. Paternally Inherited IGF2 Mutation and Growth Restriction. N Engl J Med 2015;373:349-356. Epub 2015 Jul 8.

22. de Vasconcelos Hage SR, Cendes F, Montenegro MA, Abramides DV, Guimarães CA, Guerreiro MM. Specific language impairment: linguistic and neurobiological aspects. Arq Neuropsiquiatr 2006;64:173-180. Epub 2006 Jun 9

23. Swanson MR, Wolff JJ, Elison JT, Gu H, Hazlett HC, Botteron K, Styner M, Paterson S, Gerig G, Constantino J, Dager S, Estes A, Vachet C, Piven J; IBIS Network. Splenium development and early spoken language in human infants. Dev Sci 2017;20:1-13. Epub 2015 Oct 21

24. Civier O, Kronfeld-Duenias V, Amir O, Ezrati-Vinacour R, Ben-Shachar M. Reduced fractional anisotropy in the anterior corpus callosum is associated with reduced speech fluency in persistent developmental stuttering. Brain Lang 2015;143:20-31. Epub 2015 Mar 2

25. Halgren C, Kjaergaard S, Bak M, Hansen C, El-Schich Z, Anderson $\mathrm{CM}$, Henriksen KF, Hjalgrim $\mathrm{H}$, Kirchhoff M, Bijlsma EK, Nielsen M, den Hollander NS, Ruivenkamp CA, Isidor B, Le Caignec C, Zannolli R, Mucciolo M, Renieri A, Mari F, Anderlid BM, Andrieux J, Dieux A, Tommerup N, Bache I. Corpus callosum abnormalities, intellectual disability, speech impairment, and autism in patients with haploinsufficiency of ARID1B. Clin Genet 2012;82:248-255. Epub 2011 Aug 24 